\title{
UTILIZANDO A AVALIAÇÃO COMO FERRAMENTA PARA PLANEJAMENTO DE ATIVIDADES
}

\author{
TAUBATÉ/SP JUNHO/2018
}

\author{
Juliana Marcondes Bussolotti - UNITAU - julianabussolotti@gmail.com \\ Mariana Aranha de Souza - UNITAU - profa.maaranha@gmail.com \\ Patrícia Ortiz Monteiro - UNITAU - patricia@epts.com.br \\ Susana Aparecida da Veiga - UNITAU - susana.veiga.ead@gmail.com
}

Tipo: Investigação Científica (IC)

Natureza: Relatório Final de Pesquisa

Categoria: Pesquisa e Avaliação

Setor Educacional: EDUCAÇÃO SUPERIOR

\begin{abstract}
RESUMO
O presente artigo tem como objetivo apresentar como a Avaliação desenvolvida pelo Grupo de pesquisa: Núcleo de Estudos e Pesquisas Interdisciplinares em Saberes e Práticas em Educação a Distância - NEPISPED, na Educação a Distância da Universidade de Taubaté, UNITAU foi utilizada como ferramenta para o planejamento das atividades de 2017 e 2018 pelo grupo. Qualquer avaliação é um processo sistemático de identificação de méritos e de valores, de fatos e de expectativas; é uma atividade complexa que envolve: múltiplos instrumentos; diferentes momentos; diferentes agentes, cuja finalidade maior é promover o desenvolvimento e a consolidação das instituições elevando a qualidade de suas ações e produtos.
\end{abstract}

Palavras-chave: Educação à Distância; Avaliação; Planejamento

AGRADECIMENTOS

A PRESENTE PESQUISA FAZ PARTE DAS ATIVIDADES DESENVOLVIDAS PELO NÚCLEO DE ESTUDOS E

PESQUISAS INTERDISCIPLINARES EM SABERES E PRÁTICAS EM EDUCAÇÃO À DISTÂNCIA DO

NEAD/UNIVERSIDADE DE TAUBATÉ. 


\section{Introdução}

A avaliação deve ser um processo inerente ao desenvolvimento contínuo das instituições com a finalidade de uma reflexão coletiva e adequações. Nesse sentido, ela não deve se restringir apenas a uma coleta de dados, mas deve constituir-se em um dos processos dos quais a Universidade dispõe para analisar e planejar e/ou reorganizar ações, na medida em que subsidia intervenções a partir dos resultados obtidos, objetivando qualificar as atividades de ensinar e aprender.

O intuito da avaliação deve ser o de se discutir a Instituição, quais são os seus problemas existentes e quais são suas potencialidades. É imprescindível que a partir dessas discussões sejam traçadas metas e estabelecidos planos para que se chegue ao ponto desejado. Wills (2009) afirma, falando sobre avaliação Institucional, mas que podese expandir para qualquer tipo de avaliação nas IEs, "deve ser coerente, corajosa, sábia e com o objetivo de se constituir em subsídios para tomada de decisões para melhorar a instituição (grupo GTR 2009. Unidade I apud WILLMS, p.9, 2009)".

A avaliação é compreendida enquanto projeto, processo, implantação de ações e análise de resultados. Esse conjunto de procedimentos avaliativos sempre está vinculado à tomada de decisões. Esse é o caráter político-pedagógico da avaliação. Ela emite juízos de valor sobre a instituição, seus projetos e processos.

Para Demo (1999),

Refletir é também avaliar, e avaliar é também planejar, estabelecer objetivos etc. Daí os critérios de avaliação, que condicionam seus resultados estejam sempre subordinados a finalidades e objetivos previamente estabelecidos para qualquer prática, seja ela educativa, social, política ou outra (DEMO, 1999, p.01).

O Grupo de Pesquisa "Núcleo de Estudos e Pesquisas Interdisciplinares em Saberes e Práticas em Educação a Distância - NEPISPED" da Universidade de Taubaté implantou no final de 2016 o seu primeiro processo de avaliação próprio. A proposta de reflexão construída nesse ano pretendeu avaliar o trabalho que vem sendo desenvolvido pelo grupo de Educação a Distância e refletir possíveis falhas para, assim, planejar as atividades do ano subsequente.

O trabalho tem por objetivo apresentar a experiência da Educação a Distância da Universidade de Taubaté, UNITAU no desenvolvimento de uma Avaliação das ações da EAD considerando todas as especificidades da área e a utilização da mesma como ferramenta para o planejamento das atividades que serão desenvolvidas ao longo do ano de 2017. 


\section{Metodologia}

A pesquisa foi realizada em dezembro de 2016. Era composta de 87 questões de múltipla escolha contendo espaço para críticas e sugestões. Fez um diagnóstico das atividades pedagógicas realizadas na Educação a Distância da Universidade de Taubaté no ano de 2016. A partir da coleta das informações pode-se refletir coletivamente sobre o trabalho desenvolvido e planejar as atividades do ano seguinte. $O$ questionário enviado à toda a equipe estabelecia que aqueles que desempenhassem mais de um papel na EAD optassem por responder na função mais singular em que atuava. Das 56 pessoas que receberam o questionário 42 responderam, entre os quais: 11 tutores; 3 supervisores; 14 docentes de apoio; 13 coordenadores e 1 assessor pedagógico contabilizando $75 \%$ da equipe.

\section{Revisão de Literatura}

\subsection{Avaliação e Planejamento das ações da EAD}

A Avaliação Institucional é um dos componentes do Sistema Nacional de Avaliação da Educação Superior (Sinaes) e está relacionada: à melhoria da qualidade da educação superior; à orientação da expansão de sua oferta; ao aumento permanente da sua eficácia institucional e efetividade acadêmica e social; ao aprofundamento dos compromissos e responsabilidades sociais das instituições de educação superior, por meio da valorização de sua missão pública, da promoção dos valores democráticos, do respeito à diferença e à diversidade, da afirmação da autonomia e da identidade institucional. É parte deste processo avaliativo da instituição o planejamento e gestão do seu dia a dia.

A avaliação da educação superior brasileira adquiriu novas feições com a aprovação da Lei №.10.861, de 14 de abril de 2004, que instituiu o Sinaes. Entre as alterações introduzidas destaca-se a avaliação institucional (Al), procedida em duas etapas: autoavaliação e avaliação externa.

Autoavaliação - Coordenada pela Comissão Própria de Avaliação (CPA) de cada instituição e orientada pelas diretrizes e pelo roteiro da autoavaliação institucional da CONAES.

Avaliação externa - Realizada por comissões designadas pelo INEP, a avaliação externa tem como referência os padrões de qualidade para a educação superior expressos nos instrumentos de avaliação e nos relatórios das autoavaliações. $O$ 
processo de avaliação externa independente de sua abordagem se orienta por uma visão multidimensional que busque integrar suas naturezas: formativa e de regulação numa perspectiva de globalidade.

\footnotetext{
A avaliação institucional externa e interna é vista como uma forma de garantir transparência às ações das instituições de ensino, e seus resultados podem ser encarados como uma prestação de contas destas instituições com a sociedade. Além disso, os resultados destas avaliações devem fornecer subsídios aos gestores, docentes, discentes, enfim, a todos que, de forma direta ou indireta, participam do processo educacional da instituição, para analisarem suas ações, adotarem mudanças em seus planejamentos, buscando atingir os objetivos propostos pela instituição e, acima de tudo, garantir a qualidade da educação por elas ofertada (PASOTTI, 2016).
}

Em seu conjunto, os processos avaliativos devem constituir um sistema que permita a integração das diversas dimensões da realidade avaliada, assegurando as coerências conceitual, epistemológica e prática, bem como o alcance dos objetivos dos diversos instrumentos e modalidades. A avaliação institucional "é um processo sistemático de identificação de méritos e de valores, de fatos e de expectativas; é uma atividade complexa que envolve múltiplos instrumentos; diferentes momentos; diferentes agentes" (INEP/CONAES, 2006). Sua finalidade maior é promover o desenvolvimento e a consolidação das instituições, elevando a qualidade de suas ações e produtos.

Segundo os órgãos normativos, é realizada para verificar o desempenho das instituições de educação superior em atendimento às exigências legais estabelecidas pelo Sistema Nacional de Avaliação da Educação Superior (SINAES), cujo executor é o INEP/MEC obedecendo às exigências legais reiteradas pelo Conselho Estadual de Educação de Goiás (CEE/GO), órgão regulador do Estado.

\footnotetext{
As instituições devem planejar e implementar sistemas de avaliação institucional ... Esta avaliação deve configurarse em um processo permanente e consequente, de forma a subsidiar o aperfeiçoamento dos sistemas de gestão e pedagógicos, produzindo efetivamente correção na direção e melhoria de qualidade do processo (BRASIL, MEC, 2007, pg. 17).
}

A avaliação institucional é o processo que envolve o esforço da instituição em se conhecer e ser conhecida por outros setores da sociedade e que, articulada ao planejamento, tem grande potencial para contribuir na gestão estratégica (TRIGUEIRO, 2004).

\subsubsection{A Importância da Avaliação Institucional no Planejamento de Atividades}

A avaliação institucional contribui para que os saberes dos diferentes atores envolvidos na escola sejam incorporados e reconhecidos como legítimos, intensificando a qualidade das trocas intersubjetivas que ocorrem na escola empoderando os atores locais para a 
ação. Ação que se orienta pelas "estratégias de compromisso" com o direito das crianças aprenderem ao invés de um acatamento cego às normas e regras existentes a que se obtém adesão sem comprometimento, como resposta de conveniência às "estratégias do controle" institucional (ÂNGULO, 2007).

É por intermédio do que surge na avaliação, pontos de destaque, críticas, problemas elencados, etc., que a instituição conseguirá produzir novos materiais ou elaborar novas estratégias. Nesse sentido, a avaliação do produto final ou do trabalho necessário a produzi-lo deve ser considerada uma função estratégica. Assim, toda instituição necessita dispor de mecanismos de avaliação de desempenho para conseguir propor planos de ação para desempenhos insatisfatórios.

Para Sanchez e Raphael (2006, p.10), “um processo contínuo de avaliação interna pode proporcionar à instituição a construção de conhecimentos sobre si e, desse modo, a identificação tanto de seus pontos fracos, como seus pontos fortes e, ainda, de suas potencialidades".

Compreender a avaliação institucional a partir da perspectiva processual torna-se um urgente desafio no sentido de repensar as ações realizadas a partir de uma perspectiva crítica, reflexiva e coletiva a fim de que as ações futuras possam ser planejadas de forma colaborativa e, portanto, muito mais significativas e eficazes.

Para as autoras, ainda esta perspectiva

é um dos determinantes [...] de um projeto contínuo e aberto, diante do qual todos os setores e as pessoas que o compõem participa do repensar dos objetivos, dos modos de atuação e dos resultados de sua atividade em busca da melhoria da qualidade da instituição. Essa busca de qualidade é um dos determinantes da necessidade de um projeto em que estejam configurados: o perfil do profissional a ser formado, os objetivos do curso, as mediações necessárias a seu cumprimento e as articulações internas e externas à instituição (SANCHES; RAPHAEL, 2006, p.72).

Sob esta perspectiva é inegável o papel da avaliação institucional no planejamento mais assertivo das ações que orientarão as práticas da instituição de ensino, sejam elas atreladas à dimensão pedagógica, da pesquisa, da extensão, da gestão de pessoas. da comunicação interna e externa, ou da dimensão financeira.

\section{0 que dizem os resultados da pesquisa EAD-UNITAU/2016: análise e planejamento de ações para o ano seguinte}

Com os resultados obtidos na pesquisa programou-se uma série de reuniões com o intuito de discutir entre toda a equipe os dados recebidos e as críticas colocadas para, 
após isso, realizar o planejamento anual de 2017 de cada um dos cursos oferecidos pela instituição. Esse movimento teve como princípio a análise, reflexão e planejamento colaborativos, compreendendo o NEAD como espaço de interatividade, avaliação, planejamento e redirecionamento coletivos.

A análise dos resultados da pesquisa pelos membros do NEAD, na reunião de encerramento de 2016, teve como objetivo analisar os dados da pesquisa para diagnosticar os principais problemas que levantados e planejar novas reuniões para o início do ano letivo de 2017, com o intuito de planejar as estratégias que seriam aplicadas para alcançar as principais metas estabelecidas.

Os principais pontos destacados foram: (a) construção de materiais; (b) projeto de estudos integradores; (c) supervisão e encaminhamentos para a regulação dos processos de credenciamento de polos novos, recredenciamento institucional e de polos antigos e reconhecimento e renovação dos cursos; e (d) implementação de um projeto para a preparação dos alunos para o ENADE.

\subsubsection{Construção de Materiais}

O primeiro ponto elencado como meta foi a confecção de Material de qualidade e capacitação da equipe EAD. Um dos principais materiais da EAD, que deve ser melhorada ou atualizada sempre, é a sala virtual. Ao colocar como meta "Confeccionar um material de qualidade" não significa que a equipe considere o material existente ruim, significa que tem como objetivo a melhoria e atualização constante do mesmo. A dúvida/problema que surge é como isso será realizado e o que ainda é necessário para fazer. As figuras 1 e 2 mostram que os coordenadores consideram que seus conteudistas precisam ser capacitados no uso de ferramentas da plataforma Moodle. $O$ principal motivo é inserção constante de novos plugins nas salas virtuais.

\section{Para os coordenadores de curso e conteudistas: Precisa ainda se capacitar} para uso das ferramentas da plataforma Moodle?

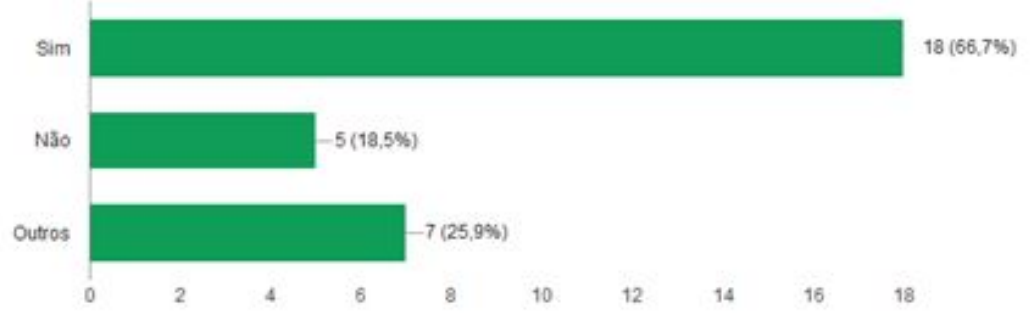

Figura 1 - A necessidade de capacitação para o uso das ferramentas da plataforma 
Moodle

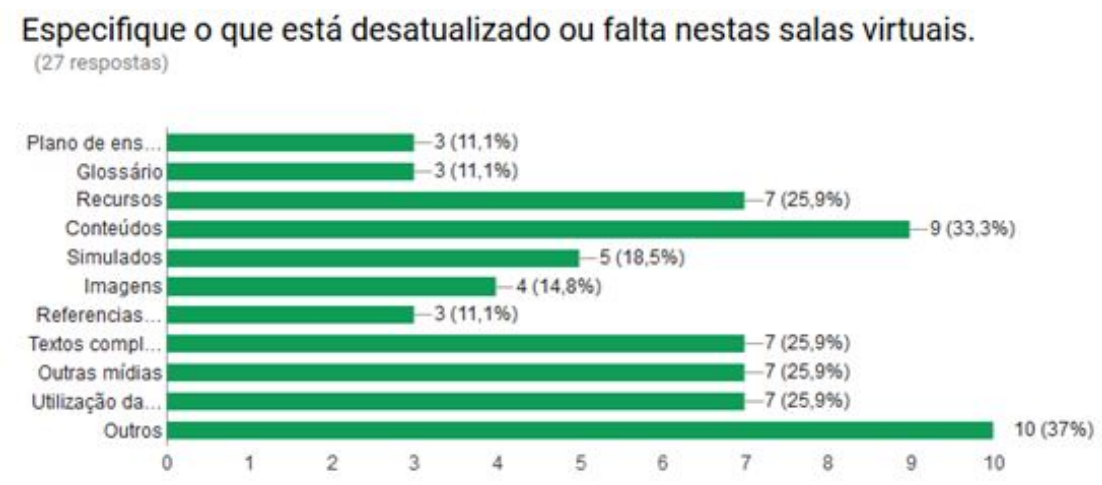

Figura 2 - Diagnóstico dos elementos que estão desatualizados nas salas virtuais.

A partir dos aspectos mencionados pelos coordenadores de curso e conteudistas, foi possível verificar quais as fragilidades acerca do uso das ferramentas oferecidas pelo moodle e, consequentemente, planejar propostas de intervenção.

Tendo posse destas fragilidades montou-se uma equipe de Objetos de Aprendizagem. Esta equipe formada ao longo do ano de 2017 iniciou suas atividades em 2018. Está composta por uma equipe multidisciplinar e coordenará a modernização das salas virtuais existentes.

\subsubsection{Projeto de Estudos Integradores}

Outro ponto levantado foi a implementação das salas virtuais de Práticas Educativas nos cursos de Licenciatura, por meio da consequente implementação do Projeto de Estudos Integradores. O Projeto de Estudos Integradores do NEAD-UNITAU é pautado no tripé da Universidade: Ensino, Pesquisa e Extensão, com valorização de práticas educativas voltadas para o exercício da docência e da gestão do ensino numa abordagem investigativa, interdisciplinar e interativa.

O Projeto tem como objetivo contribuir com a formação inicial do docente para o exercício do magistério na Educação Básica, proporcionando experiências significativas para a construção de referenciais teórico-metodológicos próprios da docência, além de favorecer sua inserção na realidade social e no contexto profissional da área de formação.

Ocorre ao longo de todo o curso, como elemento de flexibilização e integração curricular, compondo o contexto de formação teórico-prático, além da exploração e dinamização da dimensão prática nos demais módulos curriculares. O Projeto contempla 
400h de Práticas Educativas Interdisciplinares e Interativas, o Estágio Curricular Supervisionado, o Trabalho de Conclusão de Curso (TCC), as Atividades TeóricoPráticas de Aprofundamento (ATPA).

As Práticas Educativas Interdisciplinares e Interativas se constituem de quatro práticas, com carga horária de 100h cada uma, a saber: Prática Educativa de Extensão: temas socioculturais, ambientais e diversidade; Prática Educativa de Ensino: interdisciplinaridade e interatividade; Prática Educativa de Gestão do Ensino: a escola como espaço privilegiado de pesquisa; e Prática Educativa de Pesquisa: docência e pesquisa.

As atividades propostas nos projetos integradores deverão proporcionar aos estudantes, concomitantemente às disciplinas da graduação, experiências abrangentes de construção de referenciais teórico-metodológicos próprios de sua área de formação, além de oportunizar a inserção na realidade social e conhecimento do campo de atuação. Por isso, as práticas docentes deverão ocorrer ao longo do curso.

\subsubsection{Implementação de um projeto para a preparação dos alunos para o ENADE}

A partir do questionamento sobre o conhecimento sobre o relatório final do ENADE sobre o curso ao qual o docente, tutor, supervisor ou coordenador estava vinculado (e/ou de outros cursos), verificou-se que $64,1 \%$ dos respondentes não conheciam.

A primeira ação pensada nesse sentido foi o de fortalecer o sistema de avaliação processual dos alunos quanto ao seu desempenho acadêmico. Para isso, existe um grupo constituído por professores da instituição que tem como objetivo sistematizar e unificar procedimentos, métodos e ferramentas de avaliação para melhoria quantitativa e qualitativa do desempenho dos alunos da EAD-UNITAU. Este grupo, durante o primeiro semestre do ano de 2017, realizou oficinas, palestras e minicursos com o intuito de discutir qual seria a melhor forma de elaboração das provas processuais.

Os instrumentos elaborados pelo Grupo de Avaliação Interdisciplinar foram a primeira proposta para sistematizar e melhorar o processo de avaliação na Educação a Distância da Universidade de Taubaté. Quando questionados sobre a diferença entre o modelo de provas anterior e novo proposto pelo grupo a maioria dos professores e tutores respondeu que a diferença é perceptível e as opinões sobre as mudanças são, em geral, positivas, como pode ser observado na figura 3: 


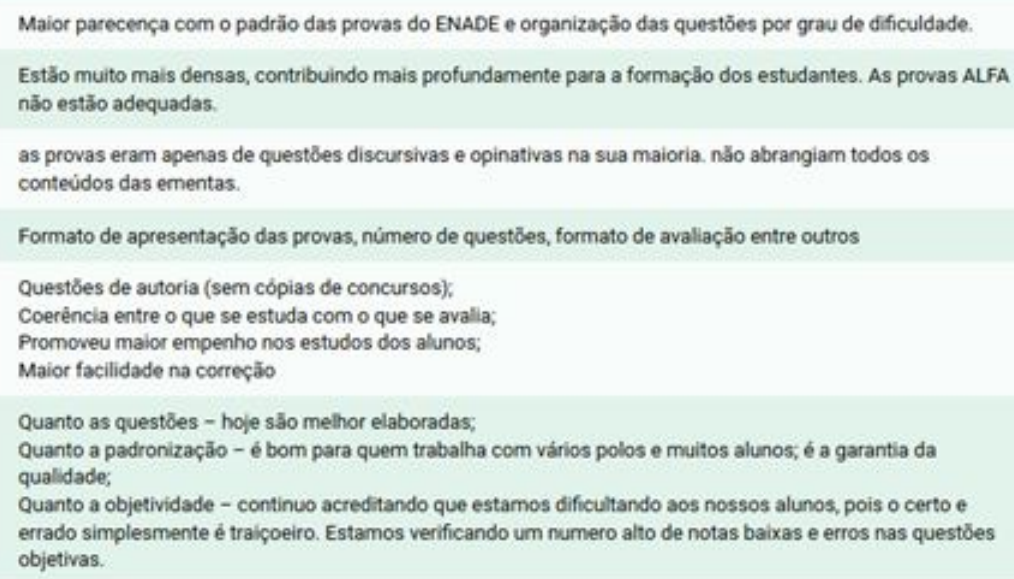

Figura 3 - O que dizem os respondentes sobre as diferenças entre os modelos de avaliação processual.

Nesse sentido, pode-se afirmar que já os respondentes percebem as diferenças existentes na elaboração das avaliações processuais, apontando-as como mais coerentes, objetivas quanto à clareza dos enunciados e aos critérios de correção. As provas propostas pelo Grupo de Avaliação começaram a ser preparadas em setembro de 2017 e aplicadas no início de 2018.

Outra ação implantada para a preparação dos alunos para o ENADE constituiu-se de oficinas onlines com os principais conteúdos abordados nas provas anteriores. As oficinas foram oferecidas ao longo do ano de 2017.

\section{Conclusão}

A Avaliação Institucional, ao ser compreendida como uma ferramenta para o diagnóstico das ações realizadas e para o planejamento das ações, permite uma clareza dos movimentos que o grupo percorre e de suas estratégias para alcançar a qualidade de suas ações.

O estudo realizado pelo Núcleo de Educação à Distância da Universidade de Taubaté no período entre os anos de 2016 e 2017, objeto deste texto, evidencia que a avaliação institucional é um processo sistemático de identificação de méritos, valores, fatos e expectativas; é uma atividade complexa que envolve múltiplos instrumentos, diferentes momentos e diferentes agentes, mas cuja finalidade maior é promover 0 desenvolvimento e a consolidação da instituição, elevando a qualidade de suas ações e produtos. 


\section{Referências}

Lei no10.861, de 14 de abril de 2004. Institui o Sistema Nacional de Avaliação da Educação Superior - SINAES e dá outras Providências. Diário Oficial da União, Brasília, DF, 15 abr. 2004. Seção 1, p. 3-4. Disponível em: . Acesso em: Agosto de 2017.

ANGULO, Felix R. O planejamento da qualificação da escola: o leigo graal da mudança educacional In: MURILLO, F.J.; REPISO, M. M et AL. A qualificação da escola. Um novo enfoque. Porto Alegre: Artmed, 2007.

BRASIL. Ministério da Educação. Sistema Nacional de Avaliação da Educação Superior SINAES: bases para uma nova proposta de avaliação da educação superior. Disponível em: . Acesso em: Agosto de 2017.

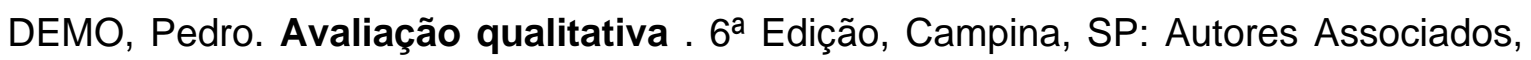
1999.

MEC/SEED. Ministério da Educação Secretaria de Educação a Distância. Referenciais de Qualidade para a Educação Superior a Distância. Agosto de 2007. Disponível em: . Acesso em 22 de abril de 2018.

PASOTTI, J. R. Avaliação Institucional: A Política de Avaliação Institucional da educação a Distância no Brasil, 2016.

SANCHES, R. C. F.; RAPHAEL, H. S. Projeto Pedagógico e avaliação institucional: articulação e importância. Revista da Rede de Avaliação Institucional da Educação Superior, Campinas, SP, v. 11, n. 1, mar., 2006. p.103-113.

TRIGUEIRO, M. G. S. A avaliação institucional e a redefinição das estruturas e modelos de gestão das instituições de ensino superior do país. Avaliação, Campinas, v. 9, n. 3, p 11-30, set. 2004.

WILLMS, N. T. Avaliação Institucional: um Conceito em Construção. Disponível em: $<$ http://www.diaadiaeducacao.pr.gov.br/portals/pde/arquivos/2024-8.pdf>. Acesso em 5 de maio de 2017. 